\title{
Study of bio-materials for removal of the oil spill
}

\author{
Eduart Wolok $^{1} \cdot$ Jamal Barafi $^{2} \cdot$ Navneet Joshi $^{3} \cdot$ Rossella Girimonte $^{4} \cdot$ Sudip Chakraborty ${ }^{4}$
}

Received: 2 October 2020 / Accepted: 13 November 2020

(C) The Author(s) 2020, corrected publication 2021

\begin{abstract}
The major battle that the human civilization is facing in the present era is regarding pollution; one of a serious threat among these pollutions is the contamination of water bodies due to oil spills. Oil spills from ships, tankers, or leaks in marine oil pipes are something that is needed to deal with to make the earth a better place. To protect the water and the environment, this oil should be removed from the water or the surface. The chances for oil spills have reduced as we have observed there is a significant change in the pattern with the decrease of the use of tankers and pipelines for oil and petroleum derivatives. The point should be that according to the researchers, the marine ecosystem is damaged even more by the other sources of pollution even though the event of oil spills is certainly much sensational. There is an urgent requirement of advanced eco-friendly tools to eliminate spilled oil. Some studies suggest that the use of organic matter may be an effective step in such an oil spilled scenario. Organic matter acts as a sorbent, a surfactant, and a separator and can make using a variety of ingredients such as organic, inorganic, synthetic, or different, but they must interact with the biological system. Some organic materials can contaminate the water more than the oil that is spread, so eco-friendly, non-toxic, low-cost organic matter should be used for oil removal and recovery. If the oil is recovered from the environmental surface, then after the successful removal of that oil, it can be conducive to sustainable development. This review summarizes the overall perspective on the potential of different biomaterials for the removal of accidentally spilled oils.
\end{abstract}

Keywords Pollution · Spilled oil · Biomaterials · International convention · Sustainable development $\cdot$ Sorbent · Accidentally spilled oil

\section{Introduction}

Worldwide, oil is considered a source of energy in various industrial applications. Many raw materials for the production of chemical and synthetic polymers are derived from oils (Almeida et al. 2019). Increasing globalization has become a

\section{Responsible Editor: Santanu Banerjee}

Sudip Chakraborty

sudip.chakraborty@unical.it

1 Faculty of Engineering, Universitas Negeri Gorontalo, Gorontalo, Indonesia

2 Al Ain University, P.O.Box: 64141, Al Ain, United Arab Emirates

3 Department of Biosciences, School of Liberal Arts and Sciences, Mody University of Science \& Technology, Lakshmangarh, Distt-Sikar, Rajasthan 332311, India

4 Dipartimento di Ingegneria Informatica, Modellistica, Elettronica e Sistemistica - DIMES, via Pietro Bucci, Cubo 42A, 87036 Rende, Cosenza (CS), Italy major cause of over-reliance on oil energy, and the use of such oils continuously pollutes the environment. Oil spill accidents have been observed very frequently for almost three decades, and several oil carriers are responsible for these accidents. These accidental spilled oils are one of the major causes of environmental pollution. Besides, salinity, temperature, and waves are also responsible for the increase in rates of oil transportation and weathering (Doshi et al. 2018). The world's biggest spilled oil incident ever happened in the Gulf of Mexico in 2010. During that time, millions of gallons of oil spilled over the oceans over more than 85 days, during which time the crude oil continued to affect marine ecosystems (Allan et al. 2012). Accidental oil spills occur due to mechanical dysfunction, transportation, utilities, and poor storage condition, which we cannot avoid (Choi and Cloud 1992). Due to the evaporation process, most of the oil disappears from the ocean, some part mixes with the surface, and some remains in the environment as a fine droplet, and they continue to pollute the environment. Crude and heavy oils like petroleum do not easily disappear from the environment unless it 
is removed by a proper method and that oil can lead to dangerous situations (Choi and Cloud 1992; Ivshina et al. 2015a; EPA 2016; Joye 2015; Wu et al. 2014; Broje and Keller 2007). Effective eco-friendly materials or technologies are needed to remove and recover oil from the surface of the environment to protect it, especially the aquatic environment, from the harmful effects of oil spills; otherwise, marine ecosystems are likely to be severely damaged. The introduction of an eco-friendly and sustainable initiative has led to the production of non-toxic, biodegradable materials along with different types of biomasses at cheaper prices for the purpose of introducing micro- to nano-sized materials, membranes, aerogel or sponges, etc. to recover and remove oil from water resources (Fingas 2012). Among the most notorious oil spills in history is the Deepwater Horizon in 2010. The incident occurred in the Gulf of Mexico and is considered the largest marine oil spill. In response to addressing the spill to protect local flora and fauna, experimental materials were in wide application, some which had not been approved for usage by the Environmental Protection Agency (EPA) to respond to oil spills (Ivshina et al. 2015a). There is an adverse health effect of spilled oil in the human body. Moderate to severe breathing trouble, eye, skin irritation, etc. may be experienced. From time to time, many scholars and researchers have altered their notion of the characteristics and influence of these oil spills on the marine ecosystem (Henkel et al. 2012; Chang et al. 2014a) and modified different types of methods and chemicals which are responsible for the oil spill (ITOPF Response Techniques 2014). The kinds of clean-up technologies are to be applied determined by the location and spill intensity (Henkel et al. 2012; Chang et al. 2014a; ITOPF Response Techniques 2014).

Based in the US, many other agencies have been in collaborative efforts with the United Nations to establish guidelines in the use of certain materials with the potential to alter the natural setting of communities. Following the widely criticized experimental oil spill removal, the EPA conducted an analysis on some of the dispersants used in the removal of the spill and have the following recommendations: firstly, the federal government of the affected region has the right to discontinue the use of any dispersant should it be proved to have negative consequences. Secondly, dispersants used must apply the subsea application process, and finally, the coast guard is responsible for approving the use of dispersant from the NCP Product Schedule. Later studies disapproved the use of dispersants in oil spill removal on grounds of increasing toxicity levels on the ocean. In 2010, EPA gave a directive to reduce the use of Corexit EC9500A and Corexit EC9527A dispersant by up to $75 \%$. Environmental regulation on the use of chemicals to disperse oil spills has led to focus drawn to more sustainable products like biosurfactants. However, the production of these substances is relatively expensive and is used minimally to contain oil spills in regions with high life (Fingas 2012).
There are international rules to deal with the issue of oil spills. For example, there is the Stockholm Declaration of 1972 on the Human Environment (EPA Oil Spill Response Techniques 2017). It gives states an obligation to put in place measures to prevent pollution of ocean waters. This obligation to states is stated in principle 7, in which all member states are required to institute mechanisms to prevent pollution and the consequential harm to human health, as well as other living organisms the most affected being animals that live in oceans and seas. The Stockholm Declaration of 1972 on the Human Environment (EPA Oil Spill Response Techniques 2017) in its principle 22 specifically addresses the issue of liability once oil spills occur in oceans and provides under international law for tackling the same. It also makes suggestions on the means of tackling pollution through environmental-friendly means.

There are also regional conventions such as the Helsinki convention which addresses more concepts, one of them being precautionary the best environmental practice. In line with this, there are various ways in which oil spills are removed. Their duration will vary depending on the type and amount of oil spill. Due to the higher density of the water than that of oil, the latter floats on the water. Its removal is therefore easier than in a case where it does sink instead of float. One of the ways for removing such spills is by using biomaterials. This entails the use of microorganisms that breakdown the oil spills and other wastes into less toxic substances. Even though it is one of the cheapest methods, it has limitations. It cannot be used in deep seas. Also, the use of microorganisms encourages the growth of vegetation in the oceans. This will hurt the animals living there.

By the use of a chemical method, in situ burning, bioremediation, and a mechanical method, it can provide an excellent result of spilled oil removal from the surface of the environment (Choi and Cloud 1992; Ivshina et al. 2015a; EPA 2016; Joye 2015; Wu et al. 2014; Broje and Keller 2007). However, studies have shown that mechanical and chemical methods are not widely used due to their high cost and ineffective oil removal capacity (Alaa El-Din et al. 2018). Management of these wastes and later cleanup have necessitated the development of technologies to conduct the cleaning. The best available technologies today include chemical treatment, gravity separation cyclone separation, and granular filtration. Despite all these technologies, biomaterials can be used to remove oil from the surface of the water. Biomaterials recover emulsified oil based on their absorption capacity. There are no adverse effects on the environment, and biomaterials are considered to be a suitable method of oil extraction for low-cost and high-quality extraction (Yati et al. 2016). Biomaterials have some beneficial properties such as hydrophobic and oleophilic nature and high adsorption capacity; they are biodegradable, environment friendly, and leaves no harmful residue after the process (Asadpour et al. 2016). It should be noted that environmental conditions will vary the performance 
of the applied biomaterial method, in addition to cost-efficiency. Most of the methods used in removing oil spillage are new, and there are limited international laws governing its usage. The rate of oil removal from the environment depends on various factors such as the type of oil, their volatile nature, the amount of oil spillage, the geographical nature, and the presence of biological communities (oil-eating germs) (Schrope 2011a; Wilson et al. 2017; Dicks 1999). Over the past few years, there has been a need to develop organic materials for efficient oil removal, so research has focused on understanding some of the bio-materials, such as lotus leaves and beetles, and the mechanism behind their hydrophobic, oleophilic nature, and super-wettable surface (Feng et al. 2002). Several surface modification techniques are understudied, and this research assumed that by using new surface modification techniques, the process cost of oil removal can be reduced manyfold by using substrates like biomaterials and paper waste (Carmody et al. 2007; Sarkar and Mahapatra 2014; Korhonen et al. 2011). This review sums up the overall view on the environment-friendly biomaterials for oil spill management and the capability of absorbing the oil in the form of absorbent, separator, and surfactants. Globally, to handle the oil spill incident, different biomaterials are extensively studied because each biomaterial cannot be suitable in all kinds of oil spill scenarios. The importance of this review is to evaluate the adsorption capacity of different biomaterials for oil spill management along with their strengths and weaknesses.

\section{Method}

As discussed earlier, spilled oil must be removed from the environment; otherwise, the environmental surface gets polluted, and due to this, along with human civilization, different animal species might face the consequences. Before knowing the beneficial aspect of biomaterials in oil spill management, three methods are widely used for the recovery of oil from the surface of the environment (Fig. 1). Different types of oil spill treatment methods are grouped as physical/mechanical, chemical, or biological (EPA 2017). Mobile floating devices such as booms fall under physical and mechanical kinds which address the oil spills and aid in stopping their movement. High-temperature booms usage can burn the oil spill on the site itself(IOGP 2016). On the contrary, removal of floating or emulsified oil from the water and the surface is done by skimmers of stationary nature (Fingas 2012). Another method, a different technology named hydrophobic meshes, can be also used for the removal of an oil spill. The work of mesh is to allow the pass-through of oil by rejecting water flow (Graham et al. 2016b; NOAA 2017). An oil spill can be broken into small droplets by using chemical spraying methods, and for small-scale oil spills, sorbent materials may be used. Now

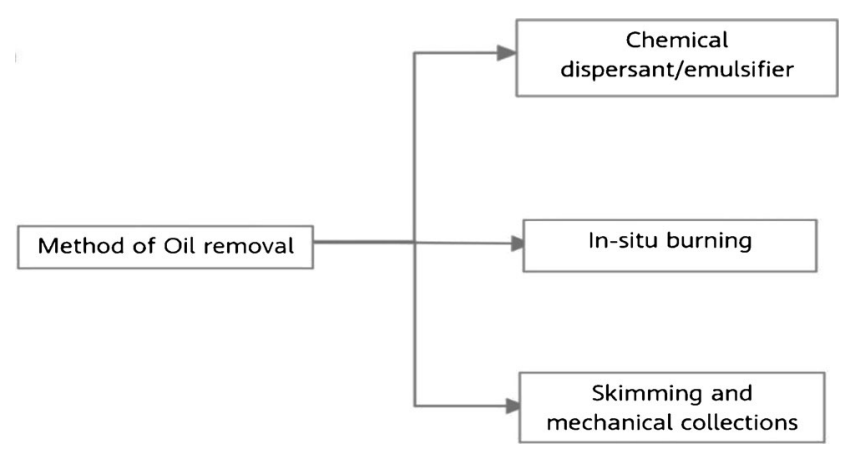

Fig. 1 Process of spilled oil removal from the environmental surface (Ivshina et al. 2015b; Schrope 2011b; Graham et al. 2016a; Walther 2014; Oil Tanker Spill Statistics 2018; Chang et al. 2014b)

comes the biological method, several of which incorporate microbes and oxygen stimulants for bacterial growth and the culmination of biodegradation of the spilled oil (Azubuike et al. 2016), whereas physiochemical methods are limited to crude oil clean up (Das and Preethy 2011; Gupta and Tai 2016).

Spilled oil can be recovered through various processes, but each of these did not have the equal ability to recover it. In the use of different chemicals to coagulate the oil and in the form of dispersant, this chemical removes the oil from the ocean. Despite having a decent result, this chemical process did not follow too much because this chemical component may be harmful to marine animals and can pollute the marine ecosystem (Goodbody-Gringley et al. 2013). Although it is the simplest and widely used technique to remove oil from the ocean, this process can emit a huge amount of dangerous smoke and this leads to environmental pollution (Evans et al. 2001). The most intensive-labor method for oil recovery is the mechanical method. This is a technique where the absorbent material absorbs the oil. This technology uses a net-like structure which is made up of absorbent material which basically encircled the pool of spilled oil and slowly shift to collect the oil from the surface (Chang et al. 2014c; Barry et al. 2017). It should be noted that the sorbent is essentially chemically and mechanically stable, for the treatment of the oil spill, in addition to environment-friendly, recyclable, low density, and impressive buoyancy properties (Gupta and Tai 2016).

Due to the chances of polluting the environment, high cost, less adsorption capacity, the physical and chemical methods are not used in any kind of oil spill scenario. So as an alternative method, biodegradable cheap biomaterials are widely used for the removal of spilled oil from the surface. Different types of biomaterials are extensively used globally as discussed below. As shown in Table 1, the natural products, kapok, rice straw, cotton, etc. are available abundantly, costeffective, biodegradable, and non-toxic and can be considered ideal as oil absorbents in oil-spill treatment.

Biomaterials which act like sorbents are mostly used for small-scale oil spilled scenario. A good oil sorbent material 
Table 1 Biomass-based sorbent used for the degradation and removal of oils (Ben and Kallel 2019; Tijani et al. 2016)

\begin{tabular}{|c|c|c|}
\hline Method & Oils & Sorbent \\
\hline White ash (Pyrolysis) & $\begin{array}{l}\text { Diesel } \\
\text { Crude oil }\end{array}$ & Rice husks \\
\hline Black ash (pyrolysis under $\mathrm{N}_{2}$ ) & $\begin{array}{l}\text { Diesel } \\
\text { Crude oil }\end{array}$ & Rice husks \\
\hline Pyrolysis at $480{ }^{\circ} \mathrm{C}$ & $\begin{array}{l}\text { Gasoline } \\
\text { Diesel } \\
\text { Light crude oil } \\
\text { Motor oil } \\
\text { Heavy crude oil }\end{array}$ & Rice husks \\
\hline Alkaline treatment & Marine diesel & Rice husks \\
\hline Drying $\left(110^{\circ} \mathrm{C}\right)$, cutting, and milling & $\begin{array}{l}\text { Motor oil } \\
\text { Vegetable oil }\end{array}$ & Silkworm cocoon waste \\
\hline Drying (sunlight and $70{ }^{\circ} \mathrm{C}$ ), crushing, and sieving & Crude oil & Banana skins \\
\hline Drying $\left(70^{\circ} \mathrm{C}\right)$ and crushing & Waste lubricating oil & Banana skins \\
\hline Cutting, sieving, washing, and drying $\left(105^{\circ}\right)$ & $\begin{array}{l}\text { Diesel oil } \\
\text { Heavy crude oil }\end{array}$ & Luffa (an agricultural waste) \\
\hline \multirow[t]{2}{*}{ Shaking flask method, autoclave, and drying } & $\begin{array}{l}\text { Mineral oil } \\
\text { Vegetable oil } \\
\text { Cutting oil }\end{array}$ & M. rouxii ( $32.7 \%$ chitosan) \\
\hline & $\begin{array}{l}\text { Mineral oil } \\
\text { Vegetable oil } \\
\text { Cutting oil }\end{array}$ & A. coerulea ( $10.4 \%$ chitosan $)$ \\
\hline Hybridization of peels with $\mathrm{NaOH}$ and drying at $70^{\circ} \mathrm{C}$ & Lubricant oil & \\
\hline & Petrol oil & Hybrid peel waste (banana skins + orange peel) \\
\hline Media & $\begin{array}{l}\text { Mineral oil } \\
\text { Vegetable oil } \\
\text { DoALL Bright-Edge Oil }\end{array}$ & Hybrid peel waste (banana skins + orange peel) \\
\hline
\end{tabular}

should have high adsorption ability and hydrophobic and oleophilic property, must ensure biodegradability, and should be reused again. These properties of biomaterials make them different in comparison with all other methods and techniques (Abdullah et al. 2010a; Adebajo et al. 2003). Natural sorbent biomaterials have a high oil removal rate and also do not harm the environment during the oil recovery process. According to the studies, some of the plants show a high affinity for oil. This is because this type of plants has wax in their body. This waxy structure makes them able to float in the water (Gupta et al. 2015; Al-Majed et al. 2012). Barley, oats, wheat, rice straw, and rice husk all come under organic sorbent biomaterials as mentioned above Table 1. These organic sorbents have higher adsorption capacity like advantages as well as some disadvantages such as they can absorb water during the oil removal process if the oil is present in an aqueous medium. Research has shown that some of the biomaterials described above have higher absorption capacity than others. For example, Kapok fiber, raw cotton, chitosan, and Chorisia speciosa. The higher oleophilic nature of Kapok fiber (20-50 g/g) or the cotton after acetylation of cellulose gives them a higher affinity towards oil and helps the biomaterial for efficiently removing the spilled oil (Choi et al. 1993; Choi and Moreau 1993; Lim and Huang 2007; Deschamps et al. 2003). Normal raw cotton can also remove the oil from the surface, but after the acetylation process, the cotton becomes more stable and biodegradable. The Chorisia speciosa shows the highest oil adsorption ability among all the biomaterials. In wet conditions, the Chorisia speciosa has less affinity towards the water as compared to all other biomaterials and that is why it is used for a more efficient oil removal process. Research has shown that due to high hydrophobicity and oleophilic nature, the Chorisia speciosa fiber can adsorb up to $85 \mathrm{~g}$ of oil per gram of adsorbent in 1 day (Amico 2010).

Chitosan can be used as an oil-removing biomaterial. It is a different form of chitin which is found in the body of many aquatic animals. Structurally, it is a charge bipolymer having a good attraction towards the opposite charge if it is present in the oil-water mixture. Chitosan is a polysaccharide containing $\mathrm{N}$-acetyl-D-glucosamine residue in its $\mathrm{C} 2$ position, and this composed structure is responsible for the electrostatic interaction between chitosan and oil-water emulsion, hence behave as an emulsifier (Aranaz et al. 2010). Chitosan is derived from 
chitin, and after a chemical and physical modification of the structure, it can become more soluble in water than before, and in this, the modified form is used in a different type of industry for the removal of contaminant from water (Pintor et al. 2016; Kyzas and Bikiaris 2015). Chemically hydrophobicity moieties can be added in a chitosan structure, and this helps to form more stable amphiphilic chitosan (Lü et al. 2015). Recent studies have shown that biomaterials such as chitosan in the form of aerogel might be found in seafood waste.

Kapok is a type of natural fiber which has excellent oilremoving capacity from the surface. It has a good amount of oil adsorption capacity due to the porous nature of this fiber and the waxy coating on their structure (Wang et al. 2012). Several surface modification techniques such as acetylation and esterification are used to increase the amount of oil adsorbed. Kapok fiber has a large number of the hydroxyl group in their native structure, and this is the main reason behind the limited oil sorption ability. However, this structure can be modified to create a superhydrophobic and oleophilic surface.

Cotton is also used for the sorption of crude oil from the surface. Cotton is cheap, is biodegradable, has good oil retention capacity, and can be reutilized again. All these properties of cotton make it a better choice for the oil removal process. Low micronaire cotton is referred to immature cotton fiber which is mostly used for oil recovery because they have higher wax content and fine fiber on their structure (Cui et al. 2002). If the cotton fiber has a high amount of cellulose deposition, that means the fiber is mature enough and it can adsorb less amount of oil. The linear density of the fiber also affects the oil recovery capacity (Montalvo Jr. 2005). Studies suggested that low micronaire cotton can adsorb more oil than normal cotton and it is economically valuable.

Like India or China, there are many countries in the world where rice is produced and served as the main source of food. Statistics show that globally, more than 600 million tons of rice is produced and one-fourth of that represents the rice husk made each year worldwide (Chandrasekhar et al. 2003). Actually, rice husk is an agricultural waste, but the presence of cellulose in its cell wall pulled the attention of the researchers. Some researchers have shown that rice husk can be used as an oil sorbent biomaterial due to the presence of cellulose in its cell walls. To reduce the environmental pollution caused by other types of oil-removing method, rice husk and rice straw are widely used for the oil spill treatment as shown in Fig. 2 (Hu and Hsieh 2014). About $30 \%$ of cellulose is present in the rice husk structure before to be extracted from the raw rice husk, and then, different modification techniques are used to achieve super-hydrophobicity and high cellulose concentration. Biodegradable property and high adsorption capacity make rice husk one of the most important biomaterials used for the oil removal process.

Walnut shells as a separant agent have shown a promising result for oil removal from the water. Walnut shells have selectivity to separate oily pollutants from the water, and that is why it is used on the filtration process. Due to their porous nature, they show different sorption capability towards the different medium. Studies have shown that viscous oil medium generally takes more time to adsorbed through the porous walnut shell, but they can effectively separate oil from the aqueous medium (Srinivasan and Viraraghavan 2010; Srinivasan and Viraraghavan 2008). Sometimes carbon fiber is used for the removal of heavy oil. Because of having smooth surface morphological characteristics and a high sorption rate of oil, carbon fiber shows almost $100 \%$ removal of oil. Then, the adsorbed oil can be recovered from the carbon fiber by doing centrifugation for a few minutes (Inagaki et al. 2002).

Apart from the abovementioned biomaterials, barley straw, sawdust, cross-link cellulose, and oat straw are also used for the oil removal process. By using these biomaterials, one can also efficiently remove oil from the surface. So sorbents and surfactants which are used in the oil removal process must have good hydrophobicity and oleophilic nature, oil retention time, selectivity, good recovery rate, cheap, eco-friendly, do not cause any pollution; also, they should be biodegradable. We have observed that two things happen during the process of removal of an oil spill. Firstly, spilled oil is left for biodegradation which is a natural and time taking procedure. Secondly, it can be removed from the environment by the application of various biodegrading agents and the operation of different technical and mechanical methods.

\section{Effect of parametric trend in oil spill removal}

\section{Particles}

A particle characterized by its size and porosity is the basis of particle mannerism of oil and water. Two types of classifications such as dispersed phase (oil) and continuous phase (aqueous/water) under small volume fraction and large volume cover up the emulsion system. Now, throwing light on strong hydrophilic particles and strong hydrophobic particles, the former get wetted only by water, and emulsion takes on an aqueous phase of dispersed particles, whereas the latter get wetted only by the oil and remain in that phase. Raw natural sorbents have low hydrophobicity which degrades oil sorption ability by increasing water uptake, but in a general sense, these sorbents are known for their incredible adsorption capacity, biodegradability, and non-toxicity when compared with synthetic sorbents. Nanoparticles and polymer-based blends are going higher up on the scale as its surface functionality and biodegradability are user friendly for removing oil alongside providing reusing facility and simple recovery (Fouad et al. 2016). If we now focus on smaller particles $(5 \mathrm{~nm}-52 \mu \mathrm{m})$ (Lam et al. 2014), these are capable of getting absorbed at the oil-water interface, specifying wetness by both water and oil, 
Fig. 2 Oil spill treatment methods based on oil recovery or oil dispersion

\section{Oil-spill treatment}

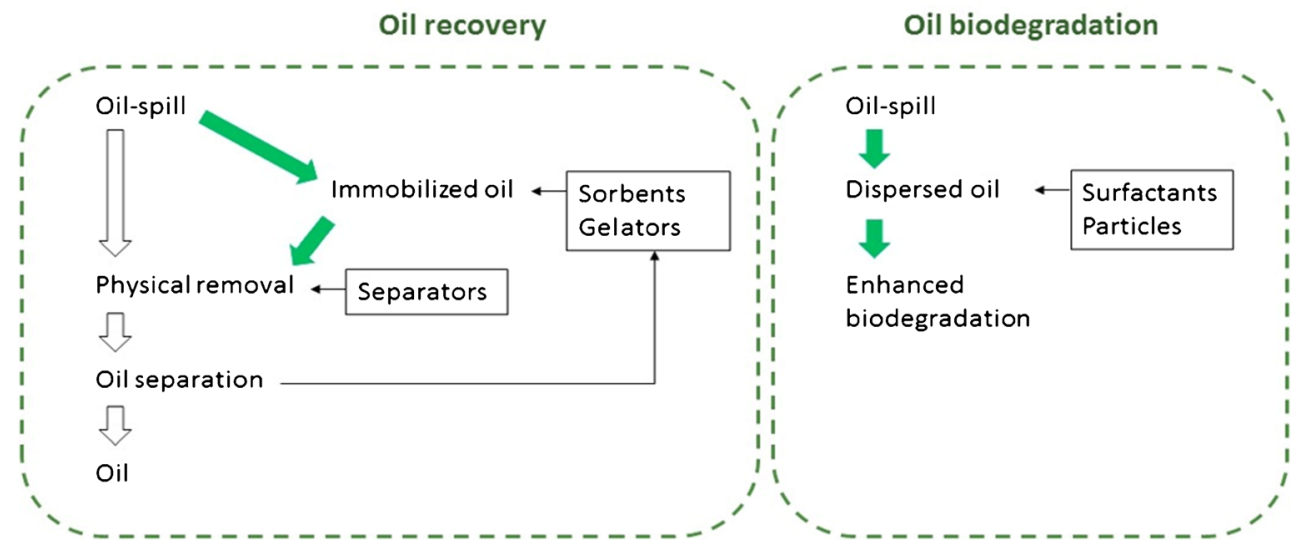

so these Pickering emulsions help in stabilizing emulsions. All these criteria need not be satisfied by particulate adsorbents as the aqueous phase cannot wet oil adsorbents, and so normally, they depend on hydrophobic preparation. Adsorbent particles are famous for their surface roughness and porosity resulting in an increased surface area of the absorbent. Pickering emulsions' (Lam et al. 2014) stability deteriorates with surface roughness and is not under desirable phenomena. The above particles mentioned can be various, acting as a surfactant, dispersing agent, emulsifying agent, herding agent, or coating materials. Table 2 signifies the various roles in the adsorption of oils.

\section{Commonly used adsorbents}

In recent years, due to the pollution caused by mechanical and chemical methods, biomaterials are widely used for the recovery of oil from the surface. Biomaterials are biodegradable, pollution-free, and cheap. Nowadays, research is going on the development of novel synthetic biomaterials which can work as a sorbent and can be efficiently used as the removing agent of oil. One biomaterial cannot be used in all kinds of oil spill scenarios because different biomaterials and different oils have their different characteristics. Some of the biomaterials can effectively remove oil at low $\mathrm{pH}$, and some of them may effortlessly work at a different environmental condition. There are various oil removal methods reported in this paper (see Table 3), such as distillation, vacuum filtration, and extraction.

Chitosan is the most important oil-removing biomaterial as mentioned above. Normally, chitosan having a $\mathrm{pH}$ of 6.8 , moisture content $2.8 \%$, a porosity of $60-65 \%$, and a degree of de-acetylation higher than $85 \%$ (Chi and Cheng 2006). Studies have shown that chitosan has a better oil removal rate at low $\mathrm{pH}(\mathrm{pH}<5)$, up to $99 \%$. The reason is that at this $\mathrm{pH}$ level, the zeta potential value which refers to the oil stability in the water is low. When the $\mathrm{pH}$ is increased, then the zeta potential value also increases which means the stability of oil in water is so high that greater force is required to separate the oil from water (Reynolds and Richards 1995). In this situation where the zeta potential value of the emulsion is high, then the removal of oil will become very difficult for the biomaterial. As the $\mathrm{pH}$ is increased $(\mathrm{pH}>7)$, the oil removal rate also decreased. Acidic $\mathrm{pH}$ helps the adsorption process and catalyzed the reaction to help the oil droplet to fit in the active site on the chitosan molecule (Ahmad et al. 2005). Chitosan can absorb up to $99.9 \mathrm{mg} / \mathrm{g}$ of oil from the oil. Among the fungal biomasses, Mucor rouxii exhibits oil adsorption capacity up to $90 \%$ and researchers thought that this higher amount of oil removal rate is achieved due to the presence of chitosan in their cell walls (Yan and Viraraghavan 2000).

Figure 3 explains how different $\mathrm{pH}$ affects the chitosan adsorption rate. As time increases, the adsorption also increases until at one time the rate becomes constant. The highest adsorption rate achieved at $5 \mathrm{pH}$ is $99.9 \%$. If the $\mathrm{pH}$ of the surface is high, then the adsorption rate will decrease as the above graph has shown. Studies have shown that $191 \mathrm{~kg}$ of chitosan is required to remove $99 \%$ of oil from the $100 \mathrm{~m}^{3}$ oily water.

Along with chitosan, Kapok fiber is also widely used for oil removal. Studies demonstrated the structure of Kapok fiber and its state as seen in the scanning electron microscope, and the porous structure of the fiber is responsible for the high adsorption rate (Dong et al. 2014). The Kapok fiber is hydrophobic in nature so it has a high affinity towards oil than water, so in the aqueous medium, the fiber tends to adsorbed oil. Since having a high water contact angle, Kapok fiber shows this super-hydrophobicity and oleophilic nature. The research suggested that its waxy structure may be responsible for the high water contact angle in Kapok fiber. Higher static contact angle and higher interfacial energy barriers between Kapok fiber and oil are also responsible for the slow oil spreading on the fiber. This is the reason behind the long 
Table 2 Different particles used in the formation of emulsions, removal, and recovery of oils

\begin{tabular}{|c|c|c|}
\hline Particles & Method & Oil \\
\hline $\begin{array}{l}\text { Chitin } \\
\text { Chitosan }\end{array}$ & Powder form & Toluene \\
\hline Chitosan & Grafting using free radical polymerization & $\begin{array}{l}\text { Gasoil } \\
\text { Mobil-1 oil } \\
\text { Light crude oil } \\
\text { Heavy crude oil }\end{array}$ \\
\hline Oil palm leaves & Blending and mixing & Crude oil \\
\hline Carboxymethyl chitosan (micro-sized) & Partial carboxymethylation & $\begin{array}{l}\text { Marine diesel } \\
\text { Diesel } \\
\text { Neste } 2 \mathrm{~T} \text { oil }\end{array}$ \\
\hline H-Oleoyl-carboxymethyl chitosan & Carboxymethylation and acylation & Wastewater of oil extraction \\
\hline Sodium salt of oleoyl carboxymethyl chitosan (micro-sized) & Carboxymethylation and acylation & Marine diesel \\
\hline Chitosan microspheres & Carboxymethylation and cross-linking & Oil in water effluents of oil industry \\
\hline Chitosan-silica hybrid (nano-sized) & Sol-gel encapsulation & $\begin{array}{l}\text { Toluene, cyclohexane, } n \text {-heptane, } \\
\text { Chloroform }\end{array}$ \\
\hline Cellulose nanocrystals (nano-sized) & Deep eutectic solvents & Marine diesel \\
\hline Bifunctionalized cellulose (nano-sized) & Oxidation and amination & Marine diesel \\
\hline $\begin{array}{l}\text { Blends of poly (vinyl alcohol) nanoparticles with chitosan or } \\
\text { starch (nano-sized) }\end{array}$ & Emulsion polymerization & $\begin{array}{l}\text { Toluene } \\
\text { Kerosene } \\
\text { Hydraulic oil }\end{array}$ \\
\hline Electrospun polyvinyl chloride/polystyrene fibers (nanofibers) & Electrospinning & $\begin{array}{l}\text { Motor oil } \\
\text { peanut oil } \\
\text { diesel }\end{array}$ \\
\hline Eugenol-based polymeric microspheres & $\begin{array}{l}\text { Suspension polymerization and } \\
\text { self-crosslinking }\end{array}$ & $\begin{array}{l}\text { Chloroform } \\
\text { Toluene } \\
\text { Gasoline } \\
\text { Diesel } \\
\text { Kerosene } \\
\text { Peanut oil }\end{array}$ \\
\hline Cellulose nanofibril and polyvinyl alcohol (aerogel microspheres) & Emulsification and freeze drying & Crude oil \\
\hline Polyvinylpyrrolidone-coated magnetite nanoparticles (nano-sized) & Hydrothermal method & MC252 oil \\
\hline $\begin{array}{l}\text { Polystyrene-coated magnetic hollow } \mathrm{Fe}_{3} \mathrm{O}_{4} \text { nanoparticles } \\
\text { (nano-sized) }\end{array}$ & $\begin{array}{l}\text { Hydrothermal synthesis and emulsion } \\
\text { polymerization }\end{array}$ & Lubricating oil \\
\hline
\end{tabular}

submergence of Kapok fiber (Abdullah et al. 2010b). If compared with cotton fiber, Kapok fiber has a high adsorption rate, but in cotton fiber, the oil will spread faster than Kapok fiber. Kapok fiber has almost $90 \%$ adsorption capacity. Kapok fiber has such a high absorption capacity that it can absorb almost twenty-five times its own weight of oil from the environment.

The below figure (Fig. 4) shows how Kapok fiber's oil retention capacity depends on the oil adsorption rate (Fig. 4). It has been observed that maximum retention of oil happens when the adsorption capacity is greater than $25 \mathrm{~g} / \mathrm{g}$. If the adsorption rate decreases less than $23 \mathrm{~g} / \mathrm{g}$, then the oil retention rate decreases gradually, and in this kind of situation, the oil retention capacity decreases to less than $85 \%$ (Cao et al. 2017).

Cotton is also used for the sorption of crude oil from the surface. Cotton cannot provide a high adsorption rate as compared to Kapok fiber and chitosan. Cotton fiber does not have a porous structure, and that is why cotton has relatively poor sorption capacity. But crude oil can be efficiently removed from the environment by the cotton fiber. Cotton has a lower contact angle, and this is one of the main reasons behind the faster spreading and adsorption in cotton. As discussed earlier, immature cotton fiber facilitates the oil adsorption rate due to its waxy structure. Studies have proved that low micronaire cotton has the highest adsorption rate as compared with all kinds of cotton fiber. The maturity of the fiber is inversely 
Table 3 Conventional sorbent used for the removal and recovery of oils

\begin{tabular}{|c|c|c|}
\hline Raw material & Synthesis & Recovery cycles \\
\hline Kapok fibers & $\begin{array}{l}\text { Polybutylmethacrylate } \\
\text { Silica nanoparticles }\end{array}$ & 6 (diesel, soybean oil, crude oil, $150 \mathrm{NS}, 20 \mathrm{cst}$ ) \\
\hline Lignin & $\begin{array}{l}\text { Organogel } \\
\text { Ambient drying }\end{array}$ & 5 (gasoline) \\
\hline Liquidambar formosana & Pyrolysis & $>10$ (paraffin and turpentine oil) \\
\hline Kapok fibers & $\begin{array}{l}\mathrm{SiO}_{2} \text { nanoparticles } \\
\text { Silanization }\end{array}$ & 8 (diesel and soybean oil) \\
\hline Cellulose foam & $\begin{array}{l}\text { Drop-casting stearic acid and graphite particles } \\
\text { Heat treatment at } 100{ }^{\circ} \mathrm{C}\end{array}$ & 15 (paraffin and motor oil) \\
\hline Kapok fibers & $\mathrm{Fe}_{3} \mathrm{O}_{4}$ nanoparticles and dopamine modification & 16 (toluene, gasoline, and diesel) \\
\hline Cotton & $\mathrm{SiO}_{2}$ nanoparticle and octadecyltrichlorosilane modification & 10 (n-hexane and chloroform) \\
\hline Poly (lactic acid) & $\begin{array}{l}\text { Vacuum } 40{ }^{\circ} \mathrm{C} \\
\text { Dioxane and ethanol solvents }\end{array}$ & 5 (hexane, diesel, gasoline, vegetable oil, and petroleum ether) \\
\hline
\end{tabular}

proportional to the oil adsorption rate as shown in Table 4 (Singh et al. 2013). So the more mature the cotton fiber is, the lower the adsorption capacity is. Low micronaire cotton has less cellulose deposition in their surface, large surface area, and twisted structure resulting in a higher oil adsorption capacity (Montalvo Jr. 2005). The maximum oil adsorption capacity of cotton observed was $15 \mathrm{~g} / \mathrm{g}$, with about $92 \%$ of oil recovered from there.

Despite being an agricultural waste material, rice husk has many utilities. Among the beneficial utility, adsorption of spilled oil from the surface of the water is an important example. For efficiently removing the spilled oil, rice husk must have some of the adsorption characteristics, in particular, the oleophilic nature of the material is one the most important. Rice husk has $70 \%$ cellulose and almost $20 \% \mathrm{SiO}_{2}$ in their structure which are responsible for the high affinity towards petroleum products. But firstly, rice husk must be pretreated by doing pyrolysis at $480{ }^{\circ} \mathrm{C}$ to form a higher porous structure. After this process caused high $\mathrm{SiO}_{2}$ content, the new porous structure becomes able for more oil retention; then, rice husk has shown high adsorption capacity. Rice husk is mainly used for removing petroleum products from the surface because

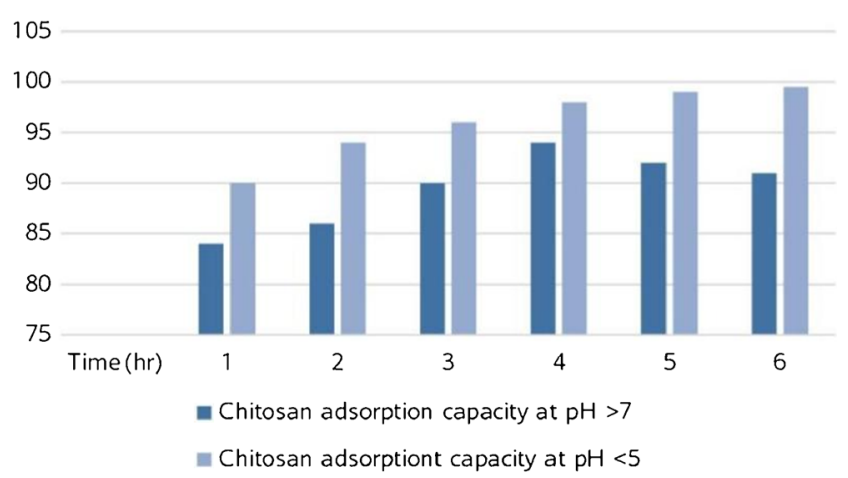

Fig. 3 Chitosan adsorption capacity at different times (Srinivasan and Viraraghavan 2010) this biomaterial is hydrophobic in nature and has good buoyancy characteristics. Low bulk density of the biomaterial helps form porous capillary in their structure, and it can affect the oil adsorption capacity. The oil absorption rate is directly proportional to the bulk density. The GC analysis of the rice husk can determine the adsorption characteristics. Carbonized rice husk contains alkane molecules on their structure, and this is the reason behind carbonized rice husk has high oil adsorption capacity. Although there are several international treaties and conventions available, but due to restrictions in different places of the work, it is hard to regulate those by international laws and agencies. It will protect not only the environment but also the sea creatures and fauna (Gandevia and Tovell 1964; United Nations 1972).

Besides all the biomaterials, walnut shell media is also used for the sorption of oil from the surface. In general, walnut shell also is characterized by high oil adsorption capacity $(96 \mathrm{mg} / \mathrm{g}$ ) (Srinivasan and Viraraghavan 2010). Some of the adsorption characteristics of walnut shell are as follows: it gets efficiently adsorbed oil at $\mathrm{pH}$ less than 6 , has $52 \%$ porosity, $0.64 \mathrm{~kg} / \mathrm{L}$ of density, and a specific gravity of 1.2-1.4. Research has shown that walnut shell exhibits different oil sorption ability to a different oily surface. For example, the highest adsorption capacity observed is for canola oil, almost $90 \mathrm{mg} / \mathrm{g}$, whereas

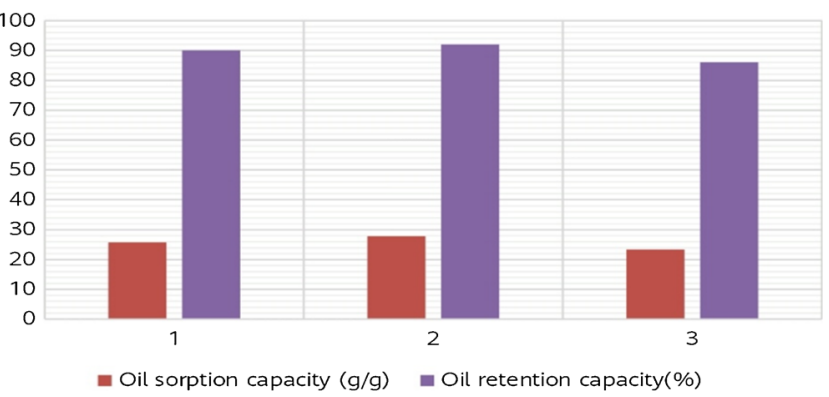

Fig. 4 The different scenario of Kapok fiber's oil retention capacity (Cao et al. 2017) 
Table 4 How oil adsorption rate depends on the maturity level of cotton fiber (Singh et al. 2013; Angelova et al. 2011)

\begin{tabular}{ll}
\hline Maturity level & Oil adsorption capacity $(\mathrm{g} / \mathrm{g})$ \\
\hline 4.6 & 30.5 \\
4.4 & 31.4 \\
4 & 32.6 \\
3.5 & 34.52 \\
3.1 & 35.83 \\
\hline
\end{tabular}

adsorption capacity for SMO oil is near $85 \mathrm{mg} / \mathrm{g}$. The higher viscosity of the oil takes more time to adsorbed through walnut shell. The porous surface of the walnut shell helps less viscous oil to penetrate or adsorbed faster (Srinivasan and Viraraghavan 2008).

\section{Challenges}

The greatest hurdle lies with the effectiveness of the absorbents in the case of the rise in oil and emulsion density, as over a while, the emulsion viscosity changes due to evaporation and emulsification.

As conventional sorbents, due to their biological origin and obtained from bio-based waste materials, they are generally eco-friendly and are available in cheaper prices. From an environmental and economic perspective, sorbents should have the capability to recover the oil, and at the same time, it can be ready for reuse. Because of low hydrophobicity, these materials exhibit low oil absorption capacity and buoyancy properties. The enhancement of these properties is possible modifying these materials, but this modification may decrease their biocompatibility. Ecofriendly and effective modification to sorbent materials is therefore necessary to increase their potentiality for the treatment of the oil spills. Emulsion can be stabilized by hydrophilic and hydrophobic particles. It happens when the wettability of particles is partial with CA 20 $120^{\circ}$. The porosity of microspheres and surface area simply commands over nano-particles in the oil absorption. To form a stable emulsion, nano-particles' dispersion rate needs to be higher.

Aerogels are considered ideal absorbent materials because of their good buoyancy properties and high absorption capacity due to low density and high surface area. Aerogels have some drawbacks so as conventional absorbents have. Biomaterials are generally amphiphilic, which they are obtained from and to infuse hydrophobic attribute; there is a requirement of further alteration. Otherwise, the aerogel synthesis process is also eco-friendly as there is no requirement of added reagents to constitute a hydrophobic absorbent. Here, in this process, the biomaterial is dissipated in water and then freezedried and pyrolyzed. On the other hand, the preparation procedure for aerogels is burdensome and add extra cost to the expenditure list. It is also not considered user-friendly in coping with large-scale oil spills. Furthermore, hydrophilic and underwater superoleophobic material separators command over hydrophobic and oleophilic substances because they have reduced in external fouling and water barrier capacity. Even though bio-based foam or membranes are capable of being broken down into innocuous substances by the action of living beings, because of lyophilization, the production along with scale-up expenditure is higher than that of mesh.

\section{Conclusion}

A variety of sorbents which are bio-based covered in this review paper are beneficial in treating oily wastewater, a steep reduction in oil content from water, re-utilization of waste, and recovery of oil. The next challenge lies in curbing the costeffective methods and producing materials which suit minimal, feasible, and eco-friendly changes but without compromising the beneficiary of the bio-based materials which are native. So non-toxicity and biodegradability must be retained. So as research has shown, some of the biomaterials have the potential ability to remove oil from the environment, and then, the oil can be recovered from it. Natural, synthetic inorganic biomaterials can function as a good sorbent for oil. As discussed, biomaterials which are used for the removal of oil have a good affinity towards oily product than water; otherwise, it can adsorb water easily from the surface of the ocean. Oil-adsorbing biomaterials must have certain characteristics such as good oleophilic and buoyancy nature, biodegradable, cheap, and easy availability. Researchers have shown that various natural fibers such as cotton and Kapok fiber have high adsorption capacity of oil. Nowadays, research is focused on developing novel biomass-derived cellulosic components for oil removal. Due to the high chances of environmental pollution, the oil must be removed from the environment because a huge amount of money is invested in this field. Most of the known oil adsorbent biomaterials have a high adsorption rate for low viscosity oil, but the sorption of high viscosity oil at a high rate is still challenging. Apart from these, in an ocean oil spilled scenario, biomaterials must have the ability to fight against big waves and strong wind power to adsorb oil from there. After the removal of oil from the surface, a proper method is required to recover the adsorbed oil from biomaterials. Research is going on the development of suitable oil-adsorbing biomaterials to overcome all these kinds of issues.

Funding Open access funding provided by Università della Calabria within the CRUI-CARE Agreement. 


\section{Compliance with ethical standards}

Conflict of interest There is no conflict of interest in this article.

Open Access This article is licensed under a Creative Commons Attribution 4.0 International License, which permits use, sharing, adaptation, distribution and reproduction in any medium or format, as long as you give appropriate credit to the original author(s) and the source, provide a link to the Creative Commons licence, and indicate if changes were made. The images or other third party material in this article are included in the article's Creative Commons licence, unless indicated otherwise in a credit line to the material. If material is not included in the article's Creative Commons licence and your intended use is not permitted by statutory regulation or exceeds the permitted use, you will need to obtain permission directly from the copyright holder. To view a copy of this licence, visit http://creativecommons.org/licenses/by/4.0/.

\section{References}

Abdullah M, Rahmah AU, Man Z (2010a) Physicochemical and sorption characteristics of Malaysian Ceiba pentandra (L.) Gaertn as a natural oil sorbent. J Hazard Mater 177(1-3):683-691

Abdullah M, Rahmah AU, Man Z (2010b) Physicochemical and sorption characteristics of (Ceiba pentandra (L.)Gaertn.) as a natural oil sorbent. Environ Technol 177:683-691

Adebajo MO, Frost RL, Kloprogge JT, Carmody O, Kokot S (2003) Porous materials for oil spill cleanup: a review of synthesis and absorbing properties. J Porous Mater 10(3):159-170

Ahmad AL, Sumathi S, Hameed BH (2005) Adsorption of residue oil from palm oil mill effluent using powder and flake chitosan: equilibrium and kinetic studies. Water Res 39:2483-2494

Alaa El-Din G, Amer AA, Malsh G, Hussein M (2018) Study on the use of banana peels for oil spill removal. Alexandria Eng J 57(3):20612068

Allan SE, Smith BW, Anderson KA (2012) Impact of the Deepwater Horizon oil Spill on bioavailable polycyclic aromatic hydrocarbons in Gulf of Mexico coastal waters. Environ Sci Technol 46:20332039

Al-Majed AA, Adebayo AR, Hossain ME (2012) A sustainable approach to controlling oil spills. J Environ Manag 113:213-227

F. Almeida, L. Meili, J. Soletti, K. Esquerre, L. Ribeiro, and C. de Farias Silva, Oil produced water treatment using sugarcane solid residue as biosorbent, Revista Mexicana deIngenier'1aQu'ımica, 18, 27-38 (2019)

Amico SC (2010) Vegetable fibers as multifunctional materials. Matéria (Rio de Janeiro) 15(2):355-363

Angelova D, Uzunov I, Uzunova S, Gigova A, Minchev L (2011) Kinetics of oil and oil products adsorption by carbonized rice husks. Chem Eng J 172:306-311

Aranaz I, Harris R, Heras A (2010) Chitosan amphiphilic derivatives. Chemistry and applications. Curr Org Chem 14:308-330

Asadpour R, Sapari NB, Isa MH, Kakooei S (2016) Acetylation of oil palm empty fruit bunch fiber as an adsorbent for removal of crude oil. Environ Sci Pollut Res 23(12):11740-11750

Azubuike CC, Chikere CB, Okpokwasili GC (2016) Bioremediation techniques-classification based on site of application: principles, advantages, limitations and prospects. World J Microbiol Biotechnol 32:180

Barry E, Mane AU, Libera JA, Elam JW, Darling SB (2017) Advanced oil sorbents using sequential infiltration synthesis. J Mater Chem A 5:2929-2935
Ben Jemaa S, Kallel A (2019) Assessment of performance of Posidonaoceanica (L.) as biosorbent for crude oil-spill cleanup in seawater. Biomed Res Int 2019:1-9. https://doi.org/10.1155/2019/ 6029654

Broje V, Keller AA (2007) Effect of operational parameters on the recovery rate of an oleophilic drum skimmer. J Hazard Mater 148:136143

Cao S, Dong T, Xu G, Wang F (2017) Oil spill cleanup by hydrophobic natural fibers. J Nat Fibers. https://doi.org/10.1080/15440478.2016. 1277820

O. Carmody, R. Frost, Y. Xi, S. Kokot, J. Colloid Interface Sci. 2007, 305,17

Chandrasekhar S, Satyanarayana KG, Pramada PN, Raghavan P, Gupta TN (2003) Processing, properties and applications of reactive silica from rice husk - an overview. J Mater Sci 38:3159-3168. https:// doi.org/10.1023/A:1025157114800

Chang SE, Stone J, Demes K, Piscitelli M (2014a) Consequences of oil spills: a review and framework for informing planning. Ecol Soc 19(2): 26

Chang SE, Stone J, Demes K, Piscitelli M (2014b) Consequences of oil spills: a review and framework for informing planning. Ecol Soc 19(2): 26

Chang SE, Stone J, Demes K, Piscitelli M (2014c) Consequences of oil spills: a review and framework for informing planning. Ecol Soc 19(2):26

Chi FH, Cheng WP (2006) Use of chitosan as coagulant to treat wastewater from milk processing plant. J Polym Environ 14:411-417

Choi HM, Cloud RM (1992) Natural sorbents in oil spill cleanup. Environ Sci Technol 26(4):772-776

Choi HM, Moreau JP (1993) Oil sorption behavior of various sorbents studied by sorption capacity measurement and environmental scanning electron microscopy. Microsc Res Tech 25(5-6):447-455

Choi HM, Kwon HJ, Moreau JP (1993) Cotton nonwovens as oil spill cleanup sorbents. Text Res J 63(4):211-218

Cui XL, Price JB, Calamari TA, Hemstreet JM, Meredith W (2002) Cotton wax and its relationship with fiber and yarn properties Part I: Wax content and fiber properties. Text Res J 72(5):399-404

Das N, Preethy C (2011) Microbial degradation of petroleum hydrocarbon contaminants: an overview. Biotechnol Res Int 2011:941810

Deschamps G, Caruel H, Borredon ME, Bonnin C, Vignoles C (2003) Oil removal from water by selective sorption on hydrophobic cotton fibers. Study of sorption properties and comparison with other cotton fiber based sorbents. Environ Sci Technol 37(5):1013-1015

Dicks, B., 1999. The environmental impact of marine oil spills - effects, Recovery and Compensation. http://www.itopf.com/fileadmin/data/ Doments/Papers/environ.pdf

Dong T, Wang F, Xu G (2014) Theoretical and experimental study on the oil sorption behavior of Kapok assemblies. Ind Crop Prod 61:325330. https://doi.org/10.1016/j.indcrop.2014.07.020

Doshi B, Sillanpää M, Kalliola S (2018) A review of bio-based materials for oil spill treatment. Water Res 135:262-277

EPA. "Dispersants | EPA Response to BP Spill in the Gulf of Mexico | US EPA,” 2016. https://archive.epa.gov/emergency/bpspill/web/html/ dispersants.html

EPA oil spill response techniques, EPA's tesponse techniques Available at https://www.epa.gov/emergency-response/epas-responsetechniques (2017)

EPA Oil Spill Response Techniques, EPA's Response TechniquesAvailable at:https://www.epa.gov/emergency-response/ epas-response-techniques(2017)

Evans DD, George W, Baum HR, Walton WD, Kevin B (2001) In situ burning of oil spills. J Res Natl Inst Stand Technol 106(1):231-278

Feng L, Li S, Li Y, Li H, Zhang L, Zhai J, Song Y, Liu B, Jiang L, Zhu D (2002) Super-hydrophobic surfaces: from natural to artificial. Adv Mater 14:1857-1860 
Fingas M (2012) The basics of oil spill cleanup, 3rd edn. Lewis Publ., Boca Raton

Fouad RR, Aljohani HA, Shoueir KR (2016) Biocompatible poly(vinyl alcohol) nanoparticle-based binary blends for oil spill. Mar Pollut Bull 46-52:112

Gandevia B, Tovell A (1964) Declaration of Helsinki. Med J Aust 2:320 321. https://doi.org/10.5694/j.1326-5377.1964.tb115781.x

Goodbody-Gringley G, Wetzel DL, Gillon D, Pulster E, Miller A, Ritchie KB (2013) Toxicity of Deepwater Horizon source oil and the chemical dispersant, Corexit ${ }^{\circledR} 9500$, to coral larvae. PLoS One 8(1):1-10

Graham L.J., Hale C., Maung-douglass E., and Sempier S.: Chemical dispersants and their role in oil spill response (2016a). Available at: https://protect-eu.mimecast.com/s/4PVCOgDgsA4O0oUPQiLn?domain=masgc.org

L. Graham, et al. Oil spill science: chemical dispersants and their role in oil spill response (2016b) s.l.: MASGP-15-015

Gupta S, Tai N-H (2016) Carbon materials as oil sorbents: a review on the synthesis and performance. J Mater Chem 4:1550-1565

Gupta D, Sarker B, Thadikaran K, John V, Maldarelli C, John G (2015) Sci Adv 1:e1400265/1-e1400265/6

Henkel JR, Sigel BJ, Taylor CM (2012) Large-scale impacts of the deepwater horizon oil spill: can local disturbance affect distant ecosystems through migratory shorebirds? Bioscience 62:676-685

Hu S, Hsieh Y-L (2014) Preparation of activated carbon and silica particles from rice straw. ACS Sustain Chem Eng 2:726-734. https://doi. org/10.1021/sc5000539

Inagaki M, Kawahara A, Nishi Y, Iwashita N (2002) Heavy oil sorption and recovery by using carbon fiber felts. Carbon 40(9):1487-1492

IOGP controlled in-situ burning of spilled oil, good practice guidelines for incident management and emergency response personnel (2016) IOGP Report 523, s.1.: s.n

ITOPF Response Techniques, (2014), Available at:http://www.itopf. $\mathrm{com} /$ knowledge-resources/documents-guides/response-techniques/

Ivshina IB, Kuyukina MS, Krivoruchko AV, Elkin AA, Makarov SO, Cunningham CJ, Peshkur TA, Atlas RM, Philp JC (2015a) Oil spill problems and sustainable response strategies through new technologies. Environ Sci Process Impacts 17:1201

Ivshina IB, Kuyukina MS, Krivoruchko AV, Elkin AA, Makarov SO, Cunningham CJ, Peshkur TA, Atlas M (2015b) Oil spill problems and sustainable response strategies through new technologies. Environ Sci Process Impacts 33:1201-1219

Joye SB (2015) Deepwater Horizon, 5 years on. Science 349:592-593

Korhonen JT, Kettunen M, Ras RHA, Ikkala O (2011) Hydrophobic nanocellulose aerogels as floating, sustainable, reusable, and recyclable oil absorbents. ACS Appl Mater Interfaces 3:1813-1816

Kyzas GZ, Bikiaris DN (2015) Recent modifications of chitosan for adsorption applications: a critical and systematic review. Mar Drugs $13: 312-337$

Lam S, Velikov KP, Velev OD (2014) Pickering stabilization of foams and emulsions with particles of biological origin. Curr Opin Colloid Interface Sci 19:490-500

Lim TT, Huang X (2007) Evaluation of hydrophobicity/oleophilicity of kapok and its performance in oily water filtration: comparison of raw and solvent-treated fibers. Ind Crop Prod 26(2):125-134
Lü T, Zhao H, Qi D, Chen Y (2015) Synthesis of a novel amphiphilic and cationic chitosan based flocculant for efficient treatment of oily wastewater. Adv Polym Technol 34(1-7):21502

Montalvo JG Jr (2005) Relationships between micronaire, fineness and maturity. Part I Fundamentals. J Cotton Sci 9(2):81-88

NOAA spill containment methods. Office of response and restoration(2017) Available at: https://response.restoration.noaa.gov/oiland-chemical-spills/oil-spills/spill-containment-methods.html

Oil Tanker Spill Statistics 2017, 2018

Pintor AMA, Vilar VJP, Botelho CMS, Boaventura RAR (2016) Oil and grease removal from wastewaters: sorption treatment as an alternative to state-of-the-art technologies. A critical review. Chem Eng J 297:229-255

Reynolds TD, Richards P (1995) Unit operations and processes in environmental engineering, Second edn. PWS Publishing Company, Boston

Sarkar A, Mahapatra S (2014) Novel hydrophobic vaterite particles for oil removal and recovery. J Mater Chem A 2:3808

Schrope M (2011a) Oil spill: deep wounds. Nature 472:152-154

Schrope M (2011b) Oil spill: deep wounds. Nature 472:152-154

Singh V, Kendall R, Hake K, Ramkumar S (2013) Crude oil sorption by raw cotton. Ind Eng Chem Res 52:6277-6281. https://doi.org/10. 1021/ie4005942

Srinivasan A, Viraraghavan T (2008) Removal of oil by walnut shell media. Bioresour Technol 99(17):8217-8220

Srinivasan A, Viraraghavan T (2010) Oil removal from water using biomaterials. Bioresour Technol 101(17):6594-6600

Tijani MM, Aqsha A, Mahinpey N (2016) Development of oil-spill sorbent from straw biomass waste: experiments and modeling studies. J Environ Manag 171:166-176

United Nations. (1972). Declaration of the United Nations conference on the human environment, Stockholm. In United Nations Environment Programme

Walther HR (2014) Clean up techniques used for coastal oil spills: an analysis of spills occurring in Santa Barbara, California, Prince William Sound, Alaska, the Sea of Japan, and the Gulf Coast. University of San Francisco, San Francisco

Wang JT, Zheng YA, Wang AQ (2012) Superhydrophobic kapok fiber oil-absorbent: preparation and high oil absorbency. Chem Eng J 213:1-7

Wilson M., Graham L., Hale C., Maung-Douglass E., Sempier S., Skelton T., and Swann L.: Oil spill science: deepwater horizonwhere did the oil go? 1-8 (2017). Available at: https://protect-eu. mimecast.com/s/pIaTCNOBOsNX6E1TRFv8t?domain=masgc.org

Wu Z-Y, Li C, Liang H-W, Zhang Y-N, Wang X, Chen J-F, Yu S-H (2014) Carbon nanofiber aerogels for emergent cleanup of oil spillage and chemical leakage under harsh conditions. Sci Rep 4:4079

Yan G, Viraraghavan T (2000) Effect of pretreatment on the bioadsorption of heavy metals on Mucor rouxii. Water SA 26(1): $119-124$

Yati I, Ozan Aydin G, Bulbul Sonmez H (2016) Cross-link edpoly(tetrahydrofuran) as promising sorbent for organic solvent/ oil spill. J Hazard Mater 309:210-218 